\title{
Knowledge of Malaria and Utilization of Insecticide-Treated Nets amongst Mothers of Under-five Children in selected Rural Communities of Nigeria's Federal Capital Territory
}

Esomonu $\mathrm{SN}^{1}$, Ossai EN², Onajole $A T^{3}$

\begin{abstract}
1Federal Capital Territory Primary Health Care Board, 9, Orlu Street, Area 3, Garki, Abuja, Nigeria. 2Department of Community Medicine, College of Health Sciences, Ebonyi State University, Abakaliki, Nigeria.

3Department of Public Health and Primary Care, College of Medicine, University of Lagos, Nigeria.
\end{abstract}

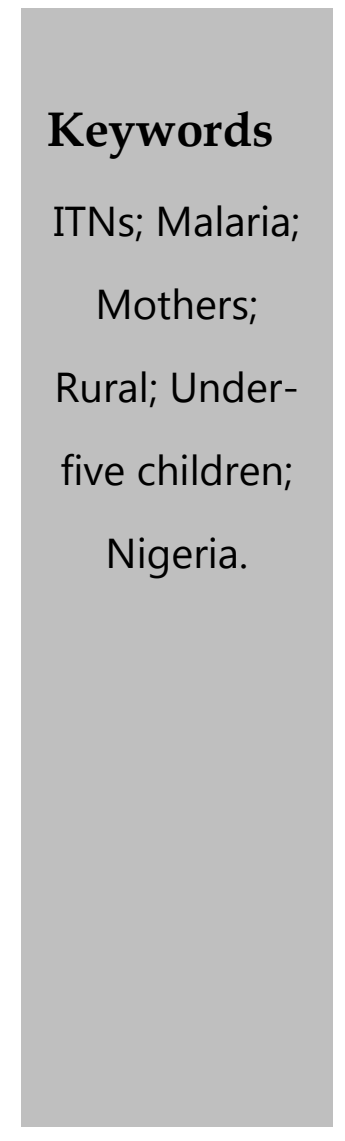

\section{ABSTRACT}

Background: Malaria is a life-threatening parasitic disease caused by the plasmodium parasite and women and under-five children are more prone to its adverse consequences. The use of insecticide-treated nets (ITNs) is recommended to reduce malaria burden in endemic communities. The study aimed to determine knowledge of malaria and utilization of insecticide-treated nets (ITNs) amongst mothers of under-five children in rural communities of Nigeria's Federal Capital Territory, and the predictors.

Methods: A community-based cross-sectional design was used. Multi-stage sampling method was used to select 160 mothers of under-five children in two rural communities. A structured questionnaire was used for data collection. Data analysis was done using SPSS statistical software version 22.0 and level of statistical significance was determined by a $\mathrm{p}$ value of $<0.05$.

Results: Mean age of respondents was 29.0 5.4 years, and majority $144(90 \%)$ of the women were married. Lower proportion of respondents had good knowledge of malaria $33(20.6 \%)$. Ninety-four (58.8\%) of respondents owned ITNs, but less than half $45(47.9 \%)$ utilized the nets. Predictors of good knowledge of malaria were having attained tertiary education [Adjusted Odds Ratio (AOR); 2.7, 95\% Confidence Interval (CI):1.1-8.1], $\mathrm{p}=0.042$, and being self-employed, (AOR; 3.4, 95\% CI: 1.1-13.1), $\mathrm{p}=0.043$ ). Predictor of utilization of ITNs was being aged 30 years and above (AOR; 2.5, 95\% CI: 1.1-6.1, $\mathrm{p}=0.031)$.

Conclusion: Lower proportions of respondents had good knowledge of malaria and utilization of ITNs. Health education of mothers on malaria and benefits of ITNs use should be intensified in the study area.
Correspondence to: Sabastine Ndubisi Esomonu Email: sabesolinks@gmail.com Phone number: 08031374350 ORCID iD: https://orcid.org/0000-0002-0382-4780

\section{INTRODUCTION}

Malaria is a life-threatening parasitic disease caused by a parasite called plasmodium. The disease is endemic in tropical areas of the world, including
Nigeria, due to the combination of rainfall, temperature and humidity conducive for the breeding and survival of the mosquito vectors. ${ }^{1}$ Other determinants of malaria distribution include poverty, quality of 
housing, access to health care, and health education. $^{2-4}$ In Africa, the burden of malaria infection is chiefly caused by Plasmodium falciparum which is the most common malarious species in the continent.5,6 Malaria is a threat to more than $40 \%$ of the world's population, and about 405,000 people died out of the more than 200 million acute cases that occurred in 2018 . About $93 \%$ of malaria cases and $94 \%$ of malaria deaths occur in the African continent. ${ }^{5}$ Children under the age of five and pregnant women are most at risk, with $P$. falciparum being the main cause of severe clinical malaria and deaths. ${ }^{1,5}$ Its major effects include low birth weight, premature births, infant mortality and anaemia in children and pregnant women. ${ }^{5-8}$

In 2018, children aged under five years accounted for $67 \%$ of global malaria deaths, and malaria accounted for $16 \%$ of low birthweights in the high burden countries, with Nigeria accounting for $24 \%$ of global malaria deaths. 5 The economic impact of malaria is enormous; about US\$ 2.7 billion was invested in malaria control and elimination efforts globally in 2018.1,5 In Nigeria, malaria accounts for $50 \%-60 \%$ of outpatient visits, with about 132 billion naira ( $\approx 471.4$ million) lost as cost of treatment and lost person-hours. ${ }^{9-10}$ The Roll Back Malaria (RBM) partnership recommends the use of insecticide-treated nets (ITNs) as part of measures to reduce the burden of malaria in vulnerable communities, particularly among pregnant women and children below the age of five years. ${ }^{11-12}$ However, research have shown that many households in several African countries (including Nigeria), particularly in rural communities, exhibit poor knowledge of malaria and modalities for its control. ${ }^{13-17}$ Related studies conducted across Africa further revealed that women in the rural communities exhibit poor knowledge of malaria and use of ITNs when compared with their urban counterparts. ${ }^{18-20}$ Successive Nigeria's Demographic and Health Surveys (DHS) however revealed variations in the utilization of ITNs amongst women in urban and rural communities, with a slightly higher average percentage use recorded in the rural areas. ${ }^{21-23}$ Some of the identified factors for poor utilization of ITNs in the rural areas were limited access and poor perception of beneficial effects of ITNs. ${ }^{24-26}$

Evidence to the cost-effectiveness of ITNs in reducing morbidity and mortality from malaria, particularly in women and children, have been well documented in previous studies. ${ }^{18,27-29}$ Similar studies across Africa further showed that good knowledge of malaria correlates positively with use of ITNs. ${ }^{30-33}$ Available studies on knowledge and prevention of malaria among women in Nigeria's Federal Capital Territory (FCT) were based in urban health facilities and mostly on the pregnant population. ${ }^{34-35}$ A study on knowledge of malaria and utilization of ITNs among mothers of underfive children in rural communities in the FCT of Nigeria will provide insight to the extent of acceptance and uptake of malaria 
control measures among the population which could serve as basis for further research. The result will further assist public health authorities in the FCT of Nigeria to improve on planning, implementation and evaluation of malaria control measures. This study aimed to determine the knowledge of malaria and utilization of ITNs amongst mothers of under-five children in selected rural communities of Nigeria's Federal Capital Territory.

\section{METHODOLOGY}

\section{Study area}

The study was carried out at GidanMangoro and Kurudu communities, which are rural communities in Abuja Municipal Area Council (AMAC) of Nigeria's Federal Capital Territory (FCT). The FCT is located at the centre of Nigeria with a land area of about 8,000 square kilometres. The territory experiences two weather conditions annually; the rainy and dry seasons. Based on the 2006 national census, the population of FCT was 1,406,239 people, with estimated population of women of childbearing age of 370,683 and under-five children of $271,770.36$ The projected population of FCT was estimated to be $3,740,080$ people, and that of AMAC was $2,473,764$ people based on annual growth rate of $9.3 \%$ in 2019 .

The municipal council is subdivided into 12 political wards of which three are located in rural areas namely; Karshi, Kabusa and Orozo wards. The council harbors most agencies of government and therefore home to the major and minor ethnic groups of Nigeria, as well as foreign nationals who constitute substantial part of the population. Gidan-Mangoro and Kurudu communities are located in Orozo ward, along the Nyanya-Karshi road of FCT. The indigenous people include Gbagyi, Gwandara and Hausa/Fulani whose main occupations are trading and farming at subsistence levels. Each of the two communities has a primary healthcare facility, as well as a public primary school. A private secondary school is located within Gidan-Mangoro community.

\section{Study design and population}

This was a community-based descriptive, cross-sectional study carried out from February to May 2016. The population comprised of mothers of under-five children who are permanent residents of the communities (residence of at least one year before the study). Those who declined consent were excluded.

\section{Sample size determination}

The minimum sample size for the study was determined by the formula for single proportions. $^{37}$ A sample size of 160 respondents was calculated for the study based on a type 1 error (a) of 0.05, a tolerable margin of error of $0.05,95 \%$ response rate and the proportion of $11.1 \%$ who owned ITNs in past Nigerian study. ${ }^{38}$

\section{Sampling technique}

A multi-stage sampling technique (involving four stages) was used to select the respondents. In the first stage, simple 
random sampling technique of balloting was used to select Abuja Municipal Area Council out of the six Councils in FCT. In the second stage, simple random sampling technique of balloting was used to select Orozo ward from the three political wards located in rural area of the Municipal Council. In the third stage, a simple random sampling of balloting was used to select two communities (Gidan-Mangoro and Kurudu) using the list of 14 communities in Orozo ward as sampling frame. In the fourth stage, a systematic random-sampling technique was used to select houses in the communities. House numbering of each of the selected two communities was done, and this served as the sampling frame. A total of 80 respondents were proportionately allocated to each of the communities. The sampling interval was determined by dividing the sampling frame by the sample size of 80 , and this determined the sequence that the houses were selected based on the numbers allocated to the houses. The index house was selected using a simple randomsampling technique of balloting. In the fifth stage, one household was selected from each house, however, in houses that had more than one household, a list of households was made and one household was selected using a simple randomsampling technique of balloting. Eligible women in the selected households were included for the study.

\section{Study instrument}

A pre-tested, structured intervieweradministered questionnaire which was designed by the researchers was used for the study. The questionnaire was formulated in English language and administered to the respondents by trained research assistants. The local languages were also used to administer the questionnaire to respondents who could not understand English by research assistants who had good command of both languages. The questionnaire contained information on respondent's bio-data and the outcome measures (such as knowledge of malaria, ownership of ITNs, and utilization of ITNs).

\section{Data management}

Data entry and analysis were done using IBM Statistical Package for Social Sciences (SPSS) version 22.0. Bivariate analysis and binary logistic regression were applied in the analysis and the level of statistical significance was determined by a p-value of $<$ 0.05. Frequency tables and crosstabulations were generated. The outcome measures of the study were good knowledge of malaria, ownership of ITNs, and utilization of ITNs. Knowledge of malaria was scored and graded using a system adapted and modified from two past studies. ${ }^{24,34}$

Ten variables were used to measure knowledge of malaria and each correct response attracted a score of one, while incorrect responses attracted a score of zero. Good knowledge of malaria was determined by a score of $\geq 6$ out of ten variables used to assess knowledge. Ownership of ITNs was assessed by sighting of ITNs in the households, while utilization 
of ITNs was assessed by ascertaining those who slept under an ITN the preceding night before the survey using the study questionnaire (those who answered "Yes" to the question of sleeping under an ITN the preceding night).

In determining the factors that affect good knowledge of malaria and utilization of ITNs, variables that had $p$-values of $\leq 0.2$ on bivariate analysis were entered into logistic regression model to determine the predictors of good knowledge and utilization based on study objectives. The result of logistic regression analysis was reported using Adjusted Odds Ratios (AOR) and 95\% Confidential Intervals (CI), and the level of statistical significance was determined by a p-value of $<0.05$.

\section{Ethical consideration}

Ethical approval was obtained from the Health Research and Ethics Committees of FCT Health Authority (FHREC: 105522). Permission was also obtained from the municipal health authority and leaders of the communities. Written informed consent was obtained from the study participants before the interviews and after a brief description of the study. Respondents were assured that participation in the study was voluntary and all the information provided through the questionnaire will be kept confidential.

\section{RESULTS}

Table 1 shows the socio-demographic characteristics of respondents. The mean age of respondents was $29.0 \pm 5.4$ years.
Highest proportion of respondents, 57 (35.6\%) were within the age group, 25-29 years. Sixty-six respondents (41.2\%) were from the Gbagyi/Gwandara ethnic group. One hundred and three respondents (64.4\%) were Christians and 144 (90\%) of them were married. The highest number had secondary education 70 (43.8\%) and were self-employed $74(46.2 \%)$. Table 2 shows knowledge of malaria among respondents. Thirty-three (20.6\%) had good knowledge of malaria. Majority 149 (93.1\%) knew that infected mosquito could transmit malaria and a lower proportion 56 (35.0\%) knew at least three methods of malaria prevention.

Tables 3 shows the factors associated with knowledge of malaria. Those women who had tertiary education were three times more likely to have good knowledge of malaria when compared with those who had secondary education and below, (AOR: 2.7, 95\% CI=1.1-8.1), $\mathrm{p}=0.042$. Also, women who were self-employed were 3.4 times more likely to have good knowledge of malaria than those who were unemployed, (AOR: 3.4, 95\% CI=1.1-13.1), $\mathrm{p}=0.043$. Table 4 shows ownership and utilization of ITNs among respondents. A higher proportion of respondents owned ITNs 94 (58.8\%) and a higher proportion of those who own ITNs 64 (68.1\%) received free nets from government health facilities and Non-Governmental Organizations (NGOs). Less than half of the respondents who own ITNs slept under them in the preceding night 45 (47.9\%). The major reasons for non-use of ITNs amongst owners of ITNs were hot weather $(38.8 \%)$ 
$(n=160)$

\begin{tabular}{|c|c|c|}
\hline \multicolumn{3}{|l|}{ Age groups (years) } \\
\hline $\begin{array}{l}<25 \\
25-29 \\
30-34 \\
\geq 35\end{array}$ & $\begin{array}{l}32 \\
57 \\
48 \\
23\end{array}$ & $\begin{array}{l}20.0 \\
35.6 \\
30.0 \\
14.4\end{array}$ \\
\hline $\begin{array}{l}\text { Ethnic Groups } \\
\text { Gbagyi/Gwandara } \\
\text { Hausa/Fulani } \\
\text { Igbo } \\
\text { Othersa }\end{array}$ & $\begin{array}{l}66 \\
28 \\
22 \\
44\end{array}$ & $\begin{array}{l}41.2 \\
17.5 \\
13.8 \\
27.5\end{array}$ \\
\hline $\begin{array}{l}\text { Religion } \\
\text { Christianity } \\
\text { Islam }\end{array}$ & $\begin{array}{l}103 \\
57\end{array}$ & $\begin{array}{l}64.4 \\
35.6\end{array}$ \\
\hline $\begin{array}{l}\text { Marital Status } \\
\text { Married } \\
\text { Singleb }^{b}\end{array}$ & $\begin{array}{l}144 \\
16\end{array}$ & $\begin{array}{l}90.0 \\
10.0\end{array}$ \\
\hline $\begin{array}{l}\text { Educational Status } \\
\text { No formal Education } \\
\text { Primary Education } \\
\text { Secondary Education } \\
\text { Post secondary education }\end{array}$ & $\begin{array}{l}24 \\
44 \\
70 \\
22\end{array}$ & $\begin{array}{l}15.0 \\
27.4 \\
43.8 \\
13.8\end{array}$ \\
\hline $\begin{array}{l}\text { Employment Status } \\
\text { Self-employed } \\
\text { Salaried employment } \\
\text { Unemployed }\end{array}$ & $\begin{array}{l}74 \\
46 \\
40\end{array}$ & $\begin{array}{l}46.2 \\
28.8 \\
25.0\end{array}$ \\
\hline $\begin{array}{l}\text { Parity } \\
1-2 \\
3-4 \\
\geq 5\end{array}$ & $\begin{array}{l}72 \\
70 \\
18\end{array}$ & $\begin{array}{l}45.0 \\
43.8 \\
11.2\end{array}$ \\
\hline $\begin{array}{l}\text { Number of Living Childre } \\
\text { One } \\
\text { Two } \\
\text { Three and Above }\end{array}$ & $\begin{array}{l}34 \\
53 \\
73\end{array}$ & $\begin{array}{l}21.3 \\
33.1 \\
45.6\end{array}$ \\
\hline
\end{tabular}

Three and Above

aOther tribes of Nigeria (Yoruba, Tiv, Igala, Ibara, Edo, Angas, Nupe, etc)

${ }^{b}$ Never Married, Separated, Divorced; Mean age of respondents $=29.0$ years $\pm 5.4 \mathrm{SD}$

and the feeling of being caged (26.5\%). Table

5 shows the factors affecting utilization of

ITNs among the respondents.

The respondents who were aged 30 years and above were 2.5 times more likely to have good utilization of ITNs when compared with those who were aged less than 30 years, (AOR: 2.5, 95\% CI=1.1-6.1), $\mathrm{p}=0.031$.

\section{DISCUSSION}

Approximately one-fifth of the respondents had good knowledge of malaria, though majority (93.1\%) knew that infected mosquitos could transmit malaria. Two similar studies in Cameroon and Nigeria recorded that $88 \%$ and $39.6 \%$ of respondents had good knowledge of malaria respectively. ${ }^{32,39}$ 
Table 2: Knowledge of malaria among the respondents

\begin{tabular}{lcc}
\hline Variables & Frequency & Percent \\
& (n=160) & \\
\hline Knew that infected mosquito could & & 93.1 \\
transmit malaria & 149 & 6.9 \\
Yes & 11 & \\
No & & 28.1 \\
Knew at least 3 symptoms/signs of malaria & 45 & 71.9 \\
Yes & 115 & \\
No & & 35.0 \\
Knew at least 3 methods of malaria prevention & 56 & 65.0 \\
Yes & 104 & \\
No & & 27.5 \\
Knew at least 3 complications of malaria & 44 & 72.5 \\
Yes & 116 & \\
No & & 20.6 \\
Knowledge of malaria & 33 & 79.4 \\
Good & 127 & \\
Poor
\end{tabular}

Table 3: Factors affecting knowledge of malaria among the respondents

\begin{tabular}{|c|c|c|c|c|c|}
\hline \multirow[t]{2}{*}{ Variables } & \multicolumn{2}{|c|}{ Knowledge of Malaria } & \multirow[t]{2}{*}{$\mathbf{P a}$} & \multirow[t]{2}{*}{$\operatorname{AOR}^{b}(95 \% \mathrm{CI})^{c}$} & \multirow[t]{2}{*}{$\mathbf{p}^{\mathbf{d}}$} \\
\hline & $\begin{array}{c}\text { Good }(n=33) \\
n(\%)\end{array}$ & $\begin{array}{c}\text { Poor }(\mathrm{n}=127) \\
\mathrm{n}(\%)\end{array}$ & & & \\
\hline \multicolumn{6}{|l|}{ Age (years) } \\
\hline$\geq 30$ & $20(27.8)$ & $52(72.2)$ & 0.043 & $1.8(0.7-4.3)$ & 0.212 \\
\hline$<30$ & $13(14.8)$ & 75 (85.2) & & 1 & \\
\hline \multicolumn{6}{|l|}{ Parity } \\
\hline $1-3$ & $26(23.6)$ & $84(76.4)$ & 0.163 & $2.2(0.8-5.8)$ & 0.122 \\
\hline$\geq 4$ & $7(14.0)$ & $43(86.0)$ & & 1 & \\
\hline \multicolumn{6}{|l|}{ Marital Status } \\
\hline Married & $32(22.2)$ & $112(77.8)$ & 0.134 & $3.4(0.4-28.1)$ & 0.250 \\
\hline Single & $1(6.2)$ & $15(93.8)$ & & 1 & \\
\hline \multicolumn{6}{|l|}{ Educational } \\
\hline \multicolumn{6}{|l|}{ Attainment } \\
\hline Tertiary Education & $10(45.5)$ & $12(54.5)$ & 0.002 & $2.7(1.1-8.1)$ & 0.042 \\
\hline$\leq$ Secondary Education & $23(16.7)$ & $115(83.3)$ & & 1 & \\
\hline \multicolumn{6}{|l|}{ Occupation } \\
\hline Self employed & $15(20.3)$ & $59(79.7)$ & & $3.4(1.1-13.1)$ & 0.043 \\
\hline Salaried employment & $15(32.6)$ & $31(67.4)$ & 0.016 & $3.4(0.8-14.2)$ & 0.046 \\
\hline Unemployed & $3(7.5)$ & 37 (92.5) & & 1 & \\
\hline \multicolumn{6}{|c|}{ Number of Living Children } \\
\hline One & $9(26.5)$ & $25(73.5)$ & 0.587 & $N^{f}$ & \\
\hline Two & $11(20.8)$ & $42(79.2)$ & & & \\
\hline Three and Above & $13(17.8)$ & $60(82.2)$ & & & \\
\hline
\end{tabular}


Table 4: Ownership and utilization of ITNs among respondents

\begin{tabular}{lcc}
\hline Variables & Frequency & Percent \\
\hline Owns an ITN (n=160) & 94 & 58.8 \\
Yes & 66 & 41.3 \\
No & & 68.1 \\
Received ITN from health facility or NGOs (n= 94) & 31.9 \\
Yes & 64 & 47.9 \\
No & 30 & 52.1 \\
Utilization of ITNs (n = 94) & & \\
Yes & 45 & 38.8 \\
No & 49 & 26.5 \\
Reason(s) for non-use of ITNs (n= 49) & & 18.4 \\
Weather was hot & 19 & 16.3 \\
I feel caged & 13 \\
No reason & 9 & \\
Other reasons & & \\
\hline
\end{tabular}

a Lack of spaces, prefers to use insecticides, and odour from the nets.

Table 5: Factors affecting utilization of ITNs among the respondents

\begin{tabular}{|c|c|c|c|c|c|}
\hline \multirow[t]{2}{*}{ Variables } & \multicolumn{2}{|c|}{ Utilization of ITNs } & \multirow[t]{2}{*}{$\mathbf{P a}$} & \multirow[t]{2}{*}{ AORb $^{b}(95 \%$ CI)c } & \multirow[t]{2}{*}{$\mathbf{p}^{\mathbf{d}}$} \\
\hline & $\begin{array}{c}\text { Good (n=45) } \\
n(\%)\end{array}$ & $\begin{array}{c}\text { Poor, } \\
\text { (n=49) } \\
\mathrm{n}(\%)\end{array}$ & & & \\
\hline \multicolumn{6}{|l|}{ Age (years) } \\
\hline$\geq 30$ & $28(60.9)$ & $18(39.1)$ & 0.014 & $2.5(1.1-6.1)$ & 0.031 \\
\hline$<30$ & $17(35.4)$ & $31(64.6)$ & & 1 & \\
\hline \multicolumn{6}{|l|}{ Parity } \\
\hline $1-3$ & $34(48.6)$ & $36(51.4)$ & 0.817 & $\mathrm{NA}^{\mathrm{e}}$ & \\
\hline$\geq 4$ & $11(45.8)$ & $13(54.2)$ & & & \\
\hline \multicolumn{6}{|l|}{ Marital Status } \\
\hline Married & $38(44.2)$ & $48(55.8)$ & 0.019 & $0.1(0.02-1.2)$ & 0.072 \\
\hline Singlef & $7(87.5)$ & $1(12.5)$ & & 1 & \\
\hline \multicolumn{6}{|c|}{ Educational Attainment } \\
\hline Tertiary Education & 7 (58.3) & $5(41.7)$ & 0.437 & NA & \\
\hline$\leq$ Secondary Education & $38(46.3)$ & $44(53.7)$ & & & \\
\hline \multicolumn{6}{|l|}{ Occupation } \\
\hline Self employed & $18(40.9)$ & $26(59.1)$ & & & \\
\hline Salaried employment & $16(57.1)$ & $12(42.9)$ & 0.395 & NA & \\
\hline Unemployed & $11(50.0)$ & $11(50.0)$ & & & \\
\hline \multicolumn{6}{|c|}{ Number of Living Children } \\
\hline One & $11(52.4)$ & $10(47.6)$ & & & \\
\hline Two & $15(51.7)$ & $14(48.3)$ & 0.694 & NA & \\
\hline Three and Above & $19(43.2)$ & $25(56.8)$ & & & \\
\hline \multicolumn{6}{|l|}{ Knowledge of malaria } \\
\hline Good & $9(50.0)$ & $9(50.0)$ & 0.841 & NA & \\
\hline Poor & $36(47.4)$ & $40(52.6)$ & & & \\
\hline
\end{tabular}

aP-value in bivariate analysis ${ }^{b} A O R=A d j u s t e d$ Odds Ratio $95 \%$ CI $=95 \%$ Confidence Interval dP-value on logistic analysis fNever Married, Separated, Divorced $\mathbf{N A}=$ Not Applicable 
Another Nigerian study revealed that a lower proportion of mothers had good knowledge of malaria (49.6\%) and $24.9 \%$ attributed malaria to mosquito bite. 40 The low proportion of respondents with good knowledge of malaria in this study could be attributed to the low proportion of respondents with higher level of education because previous studies reported that high knowledge of malaria was associated with higher educational attainment. ${ }^{32,34,41}$ It therefore follows that the low educational attainment of women in rural communities will continue to pose significant challenge to the fight against malaria. It is expected that a reasonable number of them will make conscious efforts to prevent malaria since majority knew that infected mosquitos could transmit malaria and more than one third of respondents (35\%) knew at least 3 methods of malaria prevention.

Less than half of respondents who owned ITNs slept under them in the previous night before the study. This tend to agree with the fact that ownership of ITNs does not guarantee utilization as reported in two Nigeria studies. ${ }^{24,34}$ Two similar studies in Nigeria recorded $28.2 \%$ and $7.5 \%$ utilization of ITNs respectively. ${ }^{13,19}$ Studies in Tanzania and Burkina Faso recorded $64.5 \%$ and $57.6 \%$ use of ITNs among mothers. ${ }^{41-42}$ The major reasons given by respondents for nonuse of ITNs included hot weather (38.8\%) and the feeling of being caged under the net $(26.5 \%)$. These are similar to findings from two previous studies in Nigeria where excessive heat and inconveniences were the major reasons given by women for non-use of ITNs. ${ }^{24,26}$ Furthermore, the low knowledge of malaria recorded amongst the respondents may have impacted on their utilization of ITNs because previous studies reported that good knowledge of malaria correlates positively with use of ITNs. ${ }^{30-32}$

The high ownership of ITNs (58.8\%) recorded in this study could be attributed to the high proportion of respondents (68.1\%) that received free ITNs from government health facilities and some NGOs. There is therefore the need to scale-up and sustain the distribution of free ITNs to rural and vulnerable communities so as to improve household ownership. Significant increase in household ownership and use of nets among women and children were recorded in Burkina Faso and Sierra Leone after mass distribution of ITNs. ${ }^{42-43}$ The results of study further show that those women who had tertiary education were three times more likely to have good knowledge of malaria when compared to those who had secondary education and below. This is similar to findings in Nigeria and Tanzania that higher knowledge of malaria is significantly associated with educational status of women. ${ }^{37,40}$ This suggests that educational empowerment of rural women may give significant boast to the malaria elimination efforts.

Utilization of ITNs was associated with age of respondents as those women who were aged 30 years and above were 2.5 times more likely to have good utilization of ITNs when compared with those aged less than 30 years. This may be because older 
mothers are more experienced and thus used to the application of malaria control measures. The implication is that younger mothers and their under five children may be more liable to malaria attacks. A similar Ethiopian study found that increased net use was associated with age of 25-49 years. ${ }^{31}$ However, a study in Malawi showed that use of ITNs was associated with the age of $15-19$ years. ${ }^{44}$

The reliance on responses of study participants to assess utilization of ITNs may not be the perfect approach. However, the confidence of respondents was secured and the questions were administered professionally by the trained research assistants. This study revealed lower proportions of good knowledge of malaria and utilization of ITNs among the study population. Education and occupation of respondents were associated with knowledge of malaria, while age was associated with utilization of ITNs. Health education and enlightenment of mothers on malaria and benefits of utilization of ITNs should be intensified in the study area. The FCT health authorities should sustain the distribution of free ITNs to rural communities to maintain the recorded high ownership.

Acknowledgements: The authors appreciate the co-operation from the respondents and leaders of the two communities during the study period.

Funding: The project was sponsored by the researchers.
Conflict of interest: The authors declared no potential conflicts of interest with respect to the research, authorship, and/or publication of this article.

Availability of data and materials: The data sets generated and analysed during this study are available from the corresponding author on reasonable request.

Authors' contributions: ESN and OAT conceived and designed the study. OEN and OAT supervised data collection and reviewed the manuscript. ESN conducted literature search, did the data analysis and wrote the initial draft. All authors read and approved the final draft of the manuscript.

\section{REFERENCES}

1. World Health Organization (WHO): Malaria Key Facts, January 2020. [Retrieved on $20^{\text {th }}$ February, 2020]. Available at:

https://www.who.int/news-room/factsheets/detail/malaria.

2. Aristianti V, Najmah N, Mutaha R. Social determinants of malaria in the working area of Puput public health services, West Bangka. Jurnal Ilmu Kesehatan Masyarakat. 2014; 5(2): 95-102.

3. Adefemi K, Awolaran O, Wuraola C. Social and environmental determinants of malaria in under five children in Nigeria: a review. International Journal Community Medicine and Public Health. 2015; 2(4): 345-350.

4. Hasyim H, Dale P, Groneberg DA, Kuch U, Müller R. Social determinants of malaria in an endemic area of Indonesia. Malaria Journal. 2019; 18: 134.

5. World Health Organization (WHO). World Malaria Report 2019. [Retrieved on $25^{\text {th }}$ February, 2020]. Available at: 
https://www.who.int/publicationsdetail/world-malaria-report-2019.

6. USAID Africa IRS 2019: Malaria Burden in Africa. [Retrieved 13 ${ }^{\text {th }}$ March 2020]. Available at: http://www.africairs.net/the-malariaburden-in-africa/.

7. World Health Organisation (WHO): Malaria in pregnant women, 2017. [Retrieved on 6th March 2020]. Available at:

https://www.who.int/features/2003/0 4b/en/.

8. Eisele TP, Larsen DA, Anglewicz PA, Keating J, Yukich J, Bennett A, et al. Malaria prevention in pregnancy, birthweight, and neonatal mortality: a meta-analysis of 32 national crosssectional datasets in Africa. Lancet Infectious Disease. 2012; 12(12): 942949.

9. Nigeria Malaria Factsheet. United States Embassy in Nigeria. [Retrieved on 24th June 2020]. Available at: http://www.photos.state.gov/libraries / nigeria/./DecemberMalariaFactSheet2011.pdf.

10. Federal Ministry of Health. National Guidelines for diagnosis and treatment of malaria, Abuja, National Malaria and Vector Control Division; 2011. [Retrieved on 24th June 2020]. Available at: https://docs.google.com/file/d/OB5liZv Es6EVIRnBjVklrY1ZyMkU/edit.

11. Nigeria National Malaria Elimination Programme. National Guideline on Integrated Vector Management (IVM) For Malaria Elimination in Nigeria, 2015. [Retrieved on 18th March 2020]. Available at: http://nmcp.gov.ng/aboutlearning-hub/vector-management/.

12. World Health Organization. Guidelines for treatment of malaria. Third edition. 2015. [Retrieved on 13th March 2020.] Available at:

http://www.who.int/malaria/publicatio ns/atoz/9789241549127/en/.

13. Oladokun A, Oladokun RE, Adesina OA. Knowledge and utilization of malaria control measures by pregnant and newly delivered mothers in Ibadan, Nigeria. African Health Sciences. 2011; 11(4): 573-577.

14. Arogundade ED, Adebayo SB, Anyanti J, Nwokolo E, Ladipo O, Ankomah A, et al. Relationship between care-givers' misconceptions and non-use of ITNs by under-five Nigerian children. Malaria Journal. 2011; 10: 170.

15. Akinleye SO, Ajayi IO. Knowledge of malaria and preventive measures among pregnant women attending antenatal clinics in a rural Local Government Area in Southwestern Nigeria. World Health and Population. 2011; (12): 14-22.

16. Onyeneho NG, Idemili-Aronu N, Okoye I, Ugwu C, Iremeka FU. Compliance with intermittent presumptive treatment and insecticide treated nets use during pregnancy in Enugu State, Nigeria. Maternal and Child Health Journal. 2014; 18(5): 1169-1175.

17. Kassie A, Wale M, Fekensa T. Assessment of insecticide treated bed net possession, proper utilization and the prevalence of malaria, in Dejen Woreda, East Gojam Zone, Ethiopia. Journal of Parasitology and Vector Biology. 2014; 6(7): 92-102.

18. Apinjoh TO, Anchang-Kimbi JK, Mugri RN, Tangoh DA, Nyingchu RV, Chi HF et al. The effect of insecticide-treated nets (ITNs) on Plasmodium falciparum infection in rural and semi-urban communities in the South West region of Cameroon. PLOS One. 2015; 10(2): e0116300.

19. Ankomah A, Adebayo SB, Arogundade ED, Anyanti J, Nwokolo E, Ladipo O et al. Determinants of insecticide-treated net ownership and utilization among pregnant women in Nigeria. BMC Public Health. 2012; 12: 105.

20. Ezeruigbo CFS, Okpara E, Nworie A, Uchenna U, Chibueze CI, Okeh E. Low utilization of two prophylactic measures of malaria in pregnancy (MiP) in some rural villages of Ebonyi State, Nigeria: a clarion call for enlightenment and strengthening of maternal and child health. IDOSR-Journal of Science \& Techn. 2017; 2(3): 42-48.

21. National Population Commission. Nigeria Demographic and Health Survey (NDHS) 2008. [Retrieved on 10th June 2020]. Available at:

https: / / www.dhsprogram.com/pubs/p df/FR222/FR222.pdf.

22. National Population Commission. Nigeria Demographic and Health Survey (NDHS) 2013. [Retrieved on 10th June 2020]. Available at: 
https://dhsprogram.com/pubs/pdf/FR 293/FR293.pdf.

23. National Population Commission. Nigeria Demographic and Health Survey (NDHS) 2018. [Retrieved on 10th June 2020]. Available at:

https://www.dhsprogram.com/pubs/p df/FR359/FR359.pdf.

24. Aluko JO, Oluwatosin AO. Utilization of insecticide treated nets during pregnancy among postpartum women in Ibadan, Nigeria: a cross-sectional study. BMC Pregnancy and Childbirth. 2012; 12: 21

25. Singh, M, Brown B, Rogerson SJ. Ownership and use of insecticide-treated nets during pregnancy in sub-Saharan Africa: a review. Malaria Journal. 2013; 12: 268.

26. Olajide FO, Afolabi OT, Olajide AO, Omisore AG, Omomuniniyi OA. Challenges with the use of insecticidetreated nets among pregnant women in Ife-Ijesha zone, South Western Nigeria. Journal of Primary Care and Community Health. 2011; 23(1\&2): 79-86.

27. Eisele TP, Larsen DA, Walker N, Cibulskis RE, Yukich JO, Zikusooka CM et al. Estimates of child deaths prevented from malaria prevention scale-up in Africa 2001-2010. Malaria Journal. 2012; 11(1): 1-11.

28. Eisele TP, Larsen D, Steketee RW. Protective efficacy of interventions for preventing malaria mortality in children in Plasmodium falciparum endemic areas. International Journal of Epidemiology. 2010; 39: i88-i101.

29. Lim SS, Fullman N, Stokes A, Ravishankar N, Masiye F, Murray CJL et al. Net Benefits: A multi-country analysis of observational data examining associations between insecticide- treated mosquito nets and health outcomes. PLoS Medicine. 2011; 8(9): e1001091.

30. Hwang J, Graves PM, Jima D, Reithinger R, Kachur SP. Knowledge of malaria and its association with malaria-related behaviours: Results from the Malaria Indicator Survey, Ethiopia, 2007. PLoS One. 2010; 5(7): e11692.

31. Graves PM, Ngondi JM, Hwang J, Getachew A, Teshome-Gebre T, Mosher AW et al. Factors associated with mosquito net use by individuals in households owning nets in Ethiopia. Malaria Journal. 2011; 10(1): 354.

32. Kimbi HK, Nkesa SB, NdamukongNyanga JL, Sumbele IU, Atashili J, Atanga MB. Knowledge and perceptions towards malaria prevention among vulnerable groups in the Buea Health District, Cameroon. BMC Public Health. 2014; 14(1): 883-892.

33. Ouattara AF, Raso G, Edi CVA, Utzinger $\mathrm{J}$, Tanner $\mathrm{M}$, Dagnogo $\mathrm{M}$ et al. Malaria knowledge and long-lasting insecticidal net use in rural communities of central Côte d'Ivoire. Malaria Journal. 2011; 10: 288.

34. Akaba GO, Otubu JAM, Agida ET, Onafowokan O. Knowledge and utilization of malaria preventive measures among pregnant women at a tertiary hospital in Nigeria's Federal Capital Territory. Niger. Journal of Clinical Practice. 2013; 16(2): 201-216.

35. Alli LA, Isah AY, Jamda MA, Adesokan AA. Use of intermittent preventive treatment for malaria among pregnant women in Kubwa, Abuja, Nigeria. International Journal of Tropical Disease \& Health. 2013; 3(4): 339-345.

36. Federal Republic of Nigeria official gazette. National population commission: Census 2006.

37. Onwasigwe C. Principles and methods of epidemiology. 2nd ed. Enugu; EL 'Damak Publications, 2010: 145.

38. Adebayo AM, Akinyemi OO, Cadmus EO. Ownership and utilisation of insecticidetreated mosquito nets among caregivers of under-five children and pregnant women in a rural community in Southwest Nigeria. Journal of Preventive Medicine \& Hygiene. 2014; 55(2): 58-64.

39. Oladimeji KE, Tsoka-Gwegweni JM, Ojewole E, Yunga ST. Knowledge of malaria prevention among pregnant women and non-pregnant mothers of children aged under 5 years in Ibadan, South West Nigeria. Malaria Journal. 2019; 18: 92-103.

40. Daboer JC, John C, Jamda AM, Chingle MP, Ogbonna C. Knowledge and treatment practices of malaria among mothers and caregivers of children in an urban slum in Jos, Nigeria. Nigerian Journal of Medicine. 2010; 19(2): 184187. 
41. Mazigo HD, Obasy E, Mauka W, Manyiri $\mathrm{P}$, Zinga M, Kweka EJ et al. Knowledge, attitudes, and practices about malaria and its control in rural northwest Tanzania. Malaria Research and Treatment. 2010; 2010: 1-9.

42. Ouédraogo LT, Ouédraogo I, Yaméogo A, Ouédraogo YV. Determinants of longlasting insecticidal net use in Burkina Faso after a mass distribution in the Diébougou health district. Revue d'épidémiologie et de santé publique. 2013; 61(2): 121-127.

43. Bennett A, Smith SJ, Yambasu S, Jambai A, Alemu W, Kabano A et al. Household possession and use of insecticide-treated mosquito nets in Sierra Leone 6 months after a national mass distribution campaign. PLoS One. 2012; 7(5): e37927.

44. Mwandama, D, Gutman J, Wolkon A, Luka M, Jafali J, Ali D et al. The use of intermittent preventive treatment in pregnancy and insecticide-treated bed nets for malaria prevention by women of child-bearing age in eight districts in Malawi. Malaria Journal. 2015; 14: 316. 